\title{
Cisplatin-based Concurrent Chemoradiotherapy Improved the Survival of Locoregionally Advanced Nasopharyngeal Carcinoma After Induction Chemotherapy by Reducing Early Treatment Failure
}

\author{
Xing-Li Yang \\ Sun Yat-sen University Cancer Center \\ Lu-Lu Zhang \\ Sun Yat-sen University Cancer Center \\ Jia Kou \\ Sun Yat-sen University Cancer Center \\ Guan-Qun Zhou \\ Sun Yat-sen University Cancer Center \\ Chen-Fei Wu \\ Sun Yat-sen University Cancer Center \\ Ying Sun \\ Sun Yat-sen University Cancer Center \\ Li Lin ( $\nabla$ linli@sysucc.org.cn ) \\ Sun Yat-sen University Cancer Center
}

\section{Research Article}

Keywords: Nasopharyngeal carcinoma, Chemotherapy, cisplatin dose, failure, survival

Posted Date: September 20th, 2021

DOl: https://doi.org/10.21203/rs.3.rs-899477/v1

License: (c) (i) This work is licensed under a Creative Commons Attribution 4.0 International License. Read Full License 


\section{Abstract}

\section{Purpose}

Limited data are available on the time course of treatment failures and the nature and duration of concurrent cisplatin benefit in patients with locoregionally advanced nasopharyngeal carcinoma (LANPC).

\section{Methods}

In total, 3123 patients with stage III-IVa NPC receiving IC followed by concurrent cisplatin or not were analysed. The cut-off value of treatment failure was calculated using the minimum P-value approach. Random survival forest (RSF) model was to simulate the cumulative probabilities of treatment failure (locoregional recurrence and /or distant metastasis) over-time, as well as the monthly time-specific, eventoccurring probabilities, for patients at different treatment groups.

\section{Results}

Based on subsequent prognosis, early locoregional failure (ELRF) should be defined as recurrence within 14 months $(P=1.47 \times 10-3)$, and early distant failure (EDF) should be defined as recurrence within 20 months $(P=1.95 \times 10-4)$. A cumulative cisplatin dose $(C C D)>200 \mathrm{mg} / \mathrm{m}^{2}$ independently reduced the risk of EDF (hazard ratio (HR), 0.351; 95\% confidence interval $(\mathrm{Cl}), 0.169-0.732 ; \mathrm{P}=0.005$ ). Better failure-free survival (FFS) and overall survival (OS) were observed in concurrent chemotherapy settings ([0 mg/m² $\mathrm{vs}$. $1-200 \mathrm{mg} / \mathrm{m}^{2}$ vs. $>200 \mathrm{mg} / \mathrm{m}^{2}$ ]: FFS: $70.4 \%$ vs. $74.4 \%$ vs. $82.6 \%$, all $\mathrm{P}<0.03 ;$ OS: $79.5 \%$ vs. $83.8 \%$ vs. $90.8 \%$, all $P<0.01)$. In the monthly analysis, treatment failure mainly occurred during the first 4 years, and the risk of distant failure in patients treated with concurrent chemotherapy never exceeded that of patients without concurrent chemotherapy.

\section{Conclusion}

Locoregional failure that developed within 14 months and/or distant failure within 20 months had poorer subsequent survival. Concurrent chemotherapy provides a significant FFS benefit, primarily by reducing EDF, translating into a long-term OS benefit.

\section{Background}

Nasopharyngeal carcinoma (NPC) is considered a special type of head and neck cancer due to its unique epidemiology, skewed pathology and preeminent response to treatment. In 2018, there were 129,079 new cases and 72,987 deaths worldwide[1]. Nearly $80 \%$ of patients develop locally advanced disease and are at high risk of recurrence, as patients at an early stage present anonymous symptoms in most cases[2, 3]. 
Considering of complex anatomical location and high radio- and chemo-sensitivity, platinum-based chemoradiotherapy has been the main treatment modality for non-disseminated NPC[4]. Data from largescale multi-centre phase II-III randomized controlled trials showed promising results by adding induction chemotherapy (IC) before concurrent chemoradiotherapy (CCRT) in locoregionally advanced NPC (LANPC) [5-7]. IC plus CCRT was recommended for LANPC in the latest National Comprehensive Cancer Network (NCCN) Guidelines.

Cisplatin administered during radiotherapy is supposed to further increase radiosensitivity and eliminate micrometastasis after IC. For such cases, the cumulative cisplatin dose (CCD) in concurrent chemotherapy plays an important role in conferring survival benefits. Standard practice for concurrent chemotherapy dosage included cisplatin-based regimens delivered either weekly $\left(40 \mathrm{mg} / \mathrm{m}^{2}\right)$ for 7 cycles or triweekly $\left(100 \mathrm{mg} / \mathrm{m}^{2}\right.$ or at least $\left.80 \mathrm{mg} / \mathrm{m}^{2}\right)$ for 3 cycles[4, 8,9$]$. Nevertheless, a significant fraction of patients failed to finfish the last cycles of cisplatin due to the accumulation of toxicity of radiotherapy and chemotherapy [10]. Although objectives and treatment protocols vary, $200 \mathrm{~g} / \mathrm{m}^{2}$ is the optimal cut-off value in most studies[8, 9, 11-13] and is recommended in the joint guidelines of the CSCO and ASCO [4].

Kaplan-Meier plots, typically used to present the recurrence or survival data from clinical trials, convey information regarding the absolute rate of survival at any given time point. However, a separation in survival curves is unable to convey a continuing difference in the risk of an event because an early advantage is maintained over time in such presentations. Whether concurrent cisplatin cures disease, provides continued survival benefit or temporarily inhibits tumours, thus postponing disease failure, remains unknown.

The timing of treatment failure is supposed to be significant for overall survival, and early recurrence is more likely to induce lower survival than late recurrence, which may imply tumour biology and treatment effects. However, the cut-off values of "early recurrence" varied arbitrarily from 6 to 24 months in different studies [14-18]. Based on prognosis after recurrence, pancreatic ductal adenocarcinoma, gastric cancer and rectal cancer established the optimal definition of "early recurrence" within 12 months [19-21]. In NPC patients, Li et al. confirmed the negative survival impact and summarized the characteristics of early recurrence with a threshold of 2 years based on previous studies. They also found that post-recurrence treatment options $(P=0.000)$ independently indicated post-recurrence OS. To date, a prognostic evidence-based cut-off value for NPC is lacking [16].

\section{Methods}

The aims of this study focusing on LANPC were mainly two-fold: on the one hand, to establish a cut-off value to differentiate early and late failure based on prognosis after recurrence or metastasis; and on the other hand, to investigate the duration of concurrent cisplatin benefit over follow-up time. The results of our study have the potential to guide clinical practice and follow-up. 


\section{Patient selection}

From April 2009 to December 2015, a total of 10,126 consecutive patients with newly diagnosed, histologically proven, non-disseminated NPC in Sun Yat-sen University Cancer Center (SYSUCC) were reviewed using an NPC-specific database of the big-data intelligence platform. All patients were restaged according to the 8th edition of the American Joint Committee on Cancer/International Union against Cancer (AJCC/UICC) staging system based on MRI imaging and medical records. Finally, we identified 3123 patients in this study with the following inclusion criteria: (a) III-IVa disease (according to the 8th AJCC/UICC staging system); (b) induction chemotherapy and radical intensity-modulated radiation therapy (IMRT) \pm cisplatin-based concurrent chemotherapy; and (c) no other malignancies or severe heart, lung, liver, and kidney diseases.

\section{Treatment and Study endpoints}

Cisplatin-based concurrent chemotherapy was administered triweekly for one to three cycles (80-100 $\mathrm{mg} / \mathrm{m}^{2}$ ) or weekly $\left(30-40 \mathrm{mg} / \mathrm{m}^{2}\right)$ for a maximum of 7 cycles at the initiation of IMRT. IC comprised cisplatin $\left(75 \mathrm{mg} / \mathrm{m}^{2}\right)$ with 5-fluorouracil $\left(600 \mathrm{mg} / \mathrm{m}^{2}\right)$ and docetaxel $\left(60 \mathrm{mg} / \mathrm{m}^{2}\right)$, cisplatin $\left(80 \mathrm{mg} / \mathrm{m}^{2}\right)$ with docetaxel $\left(75 \mathrm{mg} / \mathrm{m}^{2}\right)$, cisplatin $\left(80 \mathrm{mg} / \mathrm{m}^{2}\right)$ with 5 -fluorouracil $\left(1000 \mathrm{mg} / \mathrm{m}^{2}\right)$, or gemcitabine $\left(1000 \mathrm{mg} / \mathrm{m}^{2}\right)$ with cisplatin $\left(80 \mathrm{mg} / \mathrm{m}^{2}\right)$ triweekly.

Previous studies has provided the detailed description for protocol of radical IMRT and follow up strategy [22].

Overall Survival (OS, freedom from treatment initiation to death for any cause) was the primary endpoint in this study. Other endpoints were failure-free survival (FFS, freedom from treatment initiation to first event or death from any cause), distant failure-free survival (DFFS, freedom from treatment initiation to first distant metastasis), locoregional failure-free survival (LRFFS, freedom from treatment initiation to the first local or regional recurrence or both), and post-failure OS (defined as OS minus LRFFS or DFFS), respectively.

After treatment completion, patients returned to the hospital for review every 3 months during the first 2 years and every 6 months after that until death. Patients were followed up via telephone if their recent examination records were not available. Follow-up duration was defined as the date of treatment initiation until last contact or death. Posttreatment surveillance at each follow-up appointment included a comprehensive physical examination, plasma EBV DNA load, nasopharyngoscopy,and imaging assessment similar to the pretreatment examinations. Clinical suspicion of treatment failure was confirmed based on imaging assessment with or without cytological biopsies.

\section{Statistical analysis}

All statistical analyses were implemented using R version 3.4.4 (http://www.r-project.org) and the SPSS package for Windows, version 23.0 (Chicago, IL). 
A minimum P-value approach was used to calculate the cut-off value. The optimal thresholds of LRFFS and DFFS to divide the patients into an early and late failure cohort were based on survival after treatment failure. In this approach, the log-rank test was performed for different lengths of LRFFS and DFFS to determine the optimal cut-off point with the lowest $P$ value. The $R$ code is available in the supplementary files 1 . Survival curves were estimated using the Kaplan-Meier method and differences were examined by the log-rank test.

The patients' clinicopathological and treatment characteristics were compared using the $\chi 2$ or Fisher's exact test. Multivariate analysis, calculated using the Cox proportional hazards models, was used to test for independent significance by backward elimination of insignificant explanatory variables. Variables with a $P$ value of $<0.10$ were included as covariates in the Cox proportional hazards model. The criterion for statistical significance was set at P-values $<0.05$ based on two-sided tests.

A random survival forest (RSF) model was used to simulate the cumulative probabilities of treatment failure (locoregional recurrence and/or distant metastasis) over time, as well as the monthly eventoccurring probabilities, for patients in different treatment groups. We used a forest of 1000 random bootstrap survival trees to yield a stable result from right censored survival data $[23,24]$. The curves of cumulative probability represented disease failure over a period of time. Monthly specific probabilities were calculated based on the derivative of the curves. The curves were adjusted for risk factors, including sex, age, smoking status, family history, T stage, and N stage, in this study. RSF methodology was performed by the random forest SRC package (version 2.6.1)[25]. The R code referred to the study conducted by Zhou et al.[22].

\section{Result}

\section{Patient characteristics and treatment failure}

The clinical and treatment characteristics of the patients in this cohort are summarized in Table 1. The median age at diagnosis was 44 years (range, $18-76$ years); $49.1 \%(1536 / 3123)$ of subjects were at stage III, and $50.8 \%$ (1587/3123) were at stage IVa. In total, $56.3 \%$ (17658/3123) of patients received $1-2$ cycles of IC, and $43.7 \%(1365 / 3123)$ received more than 2 cycles. TPF was the most commonly used IC regimen (43.2\%; 1350/3123). For $77.3 \%$ (2414/3123) receiving concurrent cisplatin, 2230 patients received CCD $\leq 200 \mathrm{mg} / \mathrm{m}^{2}$, and only 185 patients received CCD $>200 \mathrm{mg} / \mathrm{m}^{2}$.

The median follow-up of the entire cohort was 67.5 months (interquartile range 59.5-81.5 months). During the follow-up period, $13.0 \%$ (407/3123) of patients experienced locoregional recurrence, $16.4 \%$ (511/3123) experienced distant metastasis, and 19.8\% (619/3123) died. The 5-year OS, FFS, LRFFS and DFFS values of the whole cohort were $83.2 \%, 74.0 \%, 89.9 \%$ and $84.1 \%$, respectively.

\section{Early or late treatment failure}


The P-values of differences in post-failure OS regarding various cut-off points to evaluate early locoregional recurrence or distant metastasis are shown in Figure 1. At a median follow-up of 26.9 months (interquartile range 15.7 - 40.0 months), the optimal length of early LRFFS (ELRFFS), based on subsequent post-recurrence survival, was 14 months $\left(P=1.47 \times 10^{-3}\right.$, Fig. $\left.1 \mathrm{~A}\right)$. In the current study cohort of 407 patients with locoregional recurrence, 88 patients (21.6\%) developed early locoregional failure, with 1- and 3-year post-failure OS rates of $65.9 \%$ and $34.1 \%$, and 319 patients (78.4\%) developed late locoregional failure, with 1- and 3-year post-failure OS rates of $83.8 \%$ and $46.8 \%$ ( $P=0.002$, Fig. 2A). At a median follow-up of 18.5 months (interquartile range 10.6 - 32.8 months), the optimal length of DFFS to distinguish between early and late distant failure was within 20 months $\left(P=1.95 \times 10^{-4}\right.$, Fig. 1B). For 511 patients with distant metastasis, 278 patients $(54.4 \%)$ with early metastasis had 1- and 3-year postfailure OS rates of $60.1 \%$ and $17.6 \%$, respectively, compared with $71.3 \%$ and $29.8 \%$ for the late metastasis group $(P<0.001$, Fig. $2 B)$.

Multivariable analyses of locoregional failure cohort suggest ELRFFS (hazard ratio (HR), 4.606; 95\% confidence interval $(\mathrm{Cl}), 3.391-6.257 ; \mathrm{P}<0.001)$, post failure treatment strategy $(\mathrm{P}<0.001)$ and clinical stage (HR, 1.639; $95 \% \mathrm{Cl}, 1.283-2.170 ; \mathrm{P}=0.001)$, were independently risk factors for OS (Table 2). In distance failure cohort, EDFFS (HR, 4.239; 95\% Cl, 3.408-5.273; $\mathrm{P}<0.001)$ and post failure treatment strategy $(P<0.001)$ were independently risk factors for OS (Table 3$)$.

Table 4 illustrates the multivariate analysis results of the whole cohort. The WHO histological type and overall stage were independently associated with LRFFS, in which the WHO histological type was an independent risk factor for early LRFFS (hazard ratio (HR), 0.354; 95\% confidence interval (Cl), 0.144$0.874 ; \mathrm{P}=0.024)$, and age $(\mathrm{HR}, 1.324 ; 95 \% \mathrm{Cl}, 1.063-1.649 ; \mathrm{P}=0.012)$ and clinical stage $(\mathrm{HR}, 1.427 ; 95 \%$ $\mathrm{Cl}, 1.138-1.790 ; \mathrm{P}=0.002)$ were independent risk factors for late LRFFS. For DFFS, nodal stage was an independent unfavourable risk factor $(\mathrm{HR}, 2.160 ; 95 \% \mathrm{Cl}, 1.646-2.833 ; \mathrm{P}<0.002)$. Sex, nodal stage and clinical stage were independently associated with EDFFS and LDFFS (all $P<0.02$ ). EBV DNA $>4000$ copies/ml was independently associated with an increased likelihood of EDFFS (HR, 2.152; $95 \% \mathrm{Cl}, 1.615-$ 2.867; $\mathrm{P}<0.001)$ but not LDFFS.

\section{Cisplatin-based concurrent chemotherapy and the timing of treatment failure}

Kaplan-Meier survival analysis indicated that patients with cisplatin-based concurrent chemotherapy had higher 5-year FFS and OS rates than patients without, and CCD $>200 \mathrm{mg} / \mathrm{m}^{2}$ presented a better survival than a medium-level CCD $\left(101-200 \mathrm{mg} / \mathrm{m}^{2}\right)\left(\left[0 \mathrm{mg} / \mathrm{m}^{2}\right.\right.$ vs. $1-200 \mathrm{mg} / \mathrm{m}^{2}$ vs. $\left.>200 \mathrm{mg} / \mathrm{m}^{2}\right]$ : FFS: $70.4 \%$ vs. $74.4 \%$ vs. $82.6 \%$, all $P<0.03$, Fig. $3 A$; OS: $79.5 \%$ vs. $83.8 \%$ vs. $90.8 \%$, all $P<0.01$, Fig. 3 B).

Although there was no significant difference between patients without concurrent cisplatin who received a medium dose in terms of 5 -year DFFS ( $82.2 \%$ vs. $84.1 \%, P=0.283$, Fig. 3D), CCD $>200 \mathrm{mg} / \mathrm{m}^{2}$ significantly improved DFFS compared to the other groups ([>200 mg/m $\left.\mathrm{vs} .0 \mathrm{mg} / \mathrm{m}^{2}\right]$ : $91.3 \%$ vs. $82.2 \%, P=0.010 ;\left[>200 \mathrm{mg} / \mathrm{m}^{2}\right.$ vs. $\left.1-200 \mathrm{mg} / \mathrm{m}^{2}\right]: 91.3 \%$ vs. $84.1 \%, P=0.026$, Fig. $\left.3 \mathrm{D}\right)$. However, 
no significantly different survival outcomes were observed in different applications of CCD regarding LRFFS ([0 mg/m² vs. $1-200 \mathrm{mg} / \mathrm{m}^{2}$ vs. $\left.>200 \mathrm{mg} / \mathrm{m}^{2}\right]$ : $86.1 \%$ vs. $87.6 \%$ vs. $89.4 \%$, all P > 0.05, Fig. 3 C).

Cox regression modelling predicted that cisplatin-based concurrent chemotherapy was an independent positive factor for OS, FFS and EDFFS (all $P<0.05$, Table 2). CCD $>200 \mathrm{~g} / \mathrm{m}^{2}$ was a significant factor in reducing the risk of early distant failure $(\mathrm{HR}, 0.351 ; 95 \% \mathrm{Cl}, 0.169-0.732 ; \mathrm{P}=0.005$, Table 2).

Cumulative risk is summarized in the supplementary files 2 . The monthly risk-adjusted event-occurring probability for the three groups is summarized in Figure 4. Generally, disease failure mainly occurred in the first 4 years (Fig. 4A), locoregional recurrence occurred in the 6th to 48th month (Fig. 4B), and distant metastasis occurred in approximately the first 3 years (Fig. 4C). The peak occurrence time for all endpoints was approximate in all groups, but the lowest probability of distant failure and disease failure was observed in the CCD $>200 \mathrm{~g} / \mathrm{m}^{2}$ group (Fig. 4A, C). It is worth noting that there was still a small rise in distant metastasis in patients who received concurrent cisplatin after 5 years of follow-up (Fig. 4C). For locoregional recurrence, the probability at peak was approximate, but locoregional recurrences slightly increased in patients without concurrent cisplatin after the $7^{\text {th }}$ year of follow-up (Fig. 4B).

\section{Discussion}

Presently, there is no established and evidence-based definition for early treatment failure of LANPC after radical radiotherapy. With the primary goal of classifying patients into early and late treatment failure groups, we performed a real-world study based on the statistical assessment of the best cut-off value to differentiate prognosis. In our data, early locoregional failure should be defined as recurrence within 14 months, and early distant failure should be defined as recurrence within 20 months. Since IC + CCRT was recommended for LANPC in the latest guidelines, we also investigated the prognostic effect of concurrent chemotherapy and found that cisplatin administered during radiotherapy yielded a survival benefit mainly by reducing the risk of early distant failure.

Throughout the present literature, early treatment failure is related to lower OS in a variety of malignancies $[16,18,26,27]$. However, the use of OS as the outcome indicator may be biased in determining early and late failure because patients who develop late treatment failure experience a long period without events, and thus, their OS is expected to be longer. According to previous studies, Li and his colleagues defined early local, regional or locoregional recurrence within 2 years for NPC and found that patients with early recurrence demonstrated significantly better OS than patients with late recurrence, but post-recurrence OS did not reach significance[16]. In the present study, post-failure OS was used as the primary outcome, and early failure was defined as a locoregional failure-free interval of 14 months and a distant failure-free interval of 20 months after radiotherapy. Patients who developed early disease failure suffered poorer post-failure OS than those who developed late failure, which should be ascribed to individualized hyposensitivity to chemoradiotherapy and insufficient primary treatment. 
Multivariate Cox regression analysis revealed that clinical factors, which correlative with tumor intrinsic biology and dissemination, such as histology type, tumor stage and pretreatment EBV DNA level, were independent factors for early treatment failure. In a study conducted by Groot and his colleagues, preoperatively $(>210 \mathrm{U} / \mathrm{mL})$ and postoperatively $(>37 \mathrm{U} / \mathrm{mL})$ elevated CA $19-9$ were shown to be independent factors for early recurrence in resected pancreatic ductal adenocarcinoma [19]. In intermediate-risk Papillary Thyroid Cancer, significant association was found between Pre-ablation $\mathrm{Tg}$ levels $>10 \mathrm{ng} / \mathrm{ml}$ and "early" recurrences by Olier et al [17]. Our study suggested increased pretreatment EBV DNA load was relative with OS and early distant failure, but not late failure. Theoretically, EBV DNA could be released upon cancer cell apoptosis or necrosis[28-30]. The role of pretreatment EBV DNA load for clinical prognostication has been determined in recent years[31,32], which suggests that this biomarker contain crucial additional biological information regarding tumor intrinsic aggressiveness.

Tumour biology, especially treatment sensitivity, plays an important role in failure time. Speers et al. identified 485 genes that were significantly associated with recurrence time (early vs. late) for women with breast cancer treated with radiation [18]. They also found an association between early recurrence with proliferation and EGFR concepts and late recurrence with luminal and ER signalling pathways. Our data indicated that undifferentiated squamous cell carcinoma (WHO type III) was less likely to suffer early locoregional recurrence. One of probable hypothesis is the discrepancy of NPC tumor cell radiosensitivity. Recent studies have shown that apoptosis, DNA damage repair, a hypoxic microenvironment, and autophagy can be involved in regulating radiotherapy resistance [33-35]. Moreover, post failure treatment was a significant prognosis factor for post failure survival, in which supportive treatment was associated with poorer post-recurrence OS compared with salvage surgery, reirradiation and chemotherapy [16].

Treatment strategies also influence disease failure, and thus, more attention should be paid to the initial treatment. In patients with gastric cancer after radical gastrectomy, $>3$ cycles of postoperative adjuvant chemotherapy (AC) significantly reduced the risk of early recurrence in the pathological stage III and high CAR subgroups $(16.0 \%$ vs $54.2 \%, p=0.004)$ [20]. The observations by Sargent and his colleagues, based on 18 randomized trials of patients with stage II or III colon cancer, demonstrated that AC significantly and meaningfully improved long-term survival by reducing the risk of early recurrence[36]. In the present study, concurrent chemotherapy provided a significant FFS benefit for locoregionally advanced NPC primarily by reducing the distant failure rate. Monthly analysis demonstrated that the risk of failure in each group was dominated by the early period, particularly the first 3 years. Concurrent cisplatin administration mainly decreased the magnitude of the peak in the early period of follow-up, especially reducing the risk of distant metastasis. It is well documented that distant metastasis has become the main cause of treatment failure for NPC patients[5-7]. Since EDM was related to lower survival, early DFFS improvement could translate into a longer-term OS benefit.

The interaction of radiation and cisplatin is likely to enhance cytotoxicity and thus improve locoregional control[37], but it seems that a low CCD was not sufficient to reduce the risk of locoregional relapse. In a dose-effect analysis conducted by Peng et al., a CCD of $230-270 \mathrm{mg} / \mathrm{m}^{2}$ played an important role in 
improving LRFS in patients who received CCRT alone[38]. In the combined analyses of NPC-9901 and NPC-9902, a total dose of cisplatin during the concurrent phase $\left(>200 \mathrm{mg} / \mathrm{m}^{2}\right)$ yielded a significant benefit on the LRFS and OS stage III subgroups[8]. For patients who received IC + CCRT, a high CCD yielded more beneficial antitumour effects on OS, FFS, and DFFS but not LRFFS[12, 39], which is consistent with our findings. This discrepancy may be caused by the varied population demographics, inclusion criteria and follow-up times in each study. Another possible explanation is the confounding effects of IC, even after the multivariate analysis was conducted.

$C C D \geq 200 \mathrm{mg} / \mathrm{m}^{2}$ may be indicated for high-risk patients with unfavorable response to IC. Liu et al. found that NPC patients receiving complete tumor response (CR)/partial response (PR) after IC benefited from $\geq 200 \mathrm{mg} / \mathrm{m}^{2} \mathrm{CCD}$ during CCRT; while those with stable disease (SD)/disease progression (PD) didn't. They indicated that patients with good response to IC might be inappropriate to reduce concurrent CCD because they may benefit from higher CCD. Notably, concurrent cisplatin treatment actually eradicated micrometastasis foci and postponed failure in our study. The incidence of distant metastasis climbed in the high CCD group after 5 years of follow-up, which might be due to the cessation of inhibition by chemotherapeutic agents. In such cases, longer-term follow-up is required to verify a longterm survival benefit, as effective therapy has extended survival regardless of the agent's mechanism.

This is the first study to establish an evidence-based cut-off value of disease failure for LANPC. Further investigation of the failure pattern with or without concurrent cisplatin is relevant to our understanding of tumour biology, clinical practice, and future clinical trial design. Nevertheless, there were several limitations in this study due to the retrospective nature. First, bias was inevitable as patient selection and treatment decisions were made. Second, toxicity and potential confounders, including patient compliance and social and economic factors, were unavailable in our data. Last, the limited numbers in some subsets may weaken the statistical power of the analyses.

\section{Conclusion}

In summary, there is presently no established and evidence-based threshold to differentiate between early and late failure following radical radiotherapy for LANPC. This study found locoregional failure within 14 months and distant failure within 20 months to be the optimal definition of early disease failure based on subsequent prognosis. Furthermore, in patients who receive cisplatin during radiotherapy, the risk of recurrence is dominated by the early follow-up period, particularly the first 3 years. The administration of concurrent cisplatin significantly and meaningfully reduced the risk of early distant failure and thus improved OS.

\section{Abbreviations}

Locoregionally advanced nasopharyngeal carcinoma (LANPC)

Random survival forest (RSF) 
Early locoregional failure (ELRF)

Late locoregional failure (LLRF)

Early distant failure (EDF)

Late distant failure (LDF)

Hazard ratio (HR)

Confidence interval (Cl)

Failure-free survival (FFS)

Overall survival (OS)

Induction chemotherapy (IC)

Concurrent chemoradiotherapy (CCRT)

National Comprehensive Cancer Network (NCCN)

Cumulative cisplatin dose (CCD)

Sun Yat-sen University Cancer Center (SYSUCC)

American Joint Committee on Cancer (AJCC)

International Union against Cancer (UICC)

Intensity-modulated radiation therapy (IMRT)

Distant failure-free survival (DFFS)

Locoregional failure-free survival (LRFFS)

\section{Declarations}

Ethics approval and consent to participate

As our study was based on an analysis of patients' routine clinical and treatment data, the research ethics committees of SYSUCC waived the requirement for individual informed consent.

\section{Availability of data and materials}

The authenticity of this article has been validated by uploading the key raw data onto the Research Data Deposit (RDD) public platform (http://www.researchdata.org.cn), with the RDD approval number of 
RDDA2021001983.

\section{Consent for publication}

There are no details on individuals reported within the manuscript.

\section{Conflict of interest statement}

None.

\section{Role of the funding source}

This work was supported by the National Natural Science Foundation of China [grant number 82002220区 12026601 and 81902762]. The funders had no role in study design, data collection and analysis, decision to publish, or preparation of the manuscript.

\section{Authors' contributions}

Conception and design: Li Lin, Xing-li Yang

Financial support: Lu-Lu Zhang, Li Lin, Ying Sun,

Administrative support: Ying Sun,

Provision of study materials or patients: Guan-Qun Zhou, Lu-Lu Zhang, Jia Kou, Xing-li Yang

Collection and assembly of data: Xing-Li Yang, Lu-Lu Zhang, Jia Kou, Chen-Fei Wu

Data analysis and interpretation: Xing-Li Yang, (E-mail: yangxingl@sysucc.org.cn)

Manuscript writing: All authors

Final approval of manuscript: All authors

\section{Acknowledgements}

We sincerely thank the staff members at Yidu Cloud Technology Ltd, Beijing, China (Dr. Wei Liang and Dr. Lei Shi) for their assistance with data searching on the big-data, intelligent platform.

\section{References}

1. Bray F, Ferlay J, Soerjomataram I, Siegel RL, Torre LA, Jemal A: Global cancer statistics 2018: GLOBOCAN estimates of incidence and mortality worldwide for 36 cancers in 185 countries. CA: a cancer journal for clinicians 2018, 68(6):394-424.

2. Mao YP, Xie FY, Liu LZ, Sun Y, Li L, Tang LL, Liao XB, Xu HY, Chen L, Lai SZ et al: Reevaluation of 6th edition of AJCC staging system for nasopharyngeal carcinoma and proposed improvement based on 
magnetic resonance imaging. International journal of radiation oncology, biology, physics 2009, 73(5):1326-1334.

3. Wei KR, Zheng RS, Zhang SW, Liang ZH, Li ZM, Chen WQ: Nasopharyngeal carcinoma incidence and mortality in China, 2013. Chinese journal of cancer 2017, 36(1):90.

4. Chen YP, Ismaila N, Chua MLK, Colevas AD, Haddad R, Huang SH, Wee JTS, Whitley AC, Yi JL, Yom SS et al: Chemotherapy in Combination With Radiotherapy for Definitive-Intent Treatment of Stage IIIVA Nasopharyngeal Carcinoma: CSCO and ASCO Guideline. Journal of clinical oncology: official journal of the American Society of Clinical Oncology 2021:Jc02003237.

5. Zhang Y, Chen L, Hu GQ, Zhang N, Zhu XD, Yang KY, Jin F, Shi M, Chen YP, Hu WH et al: Gemcitabine and Cisplatin Induction Chemotherapy in Nasopharyngeal Carcinoma. The New England journal of medicine 2019, 381(12):1124-1135.

6. Sun Y, Li WF, Chen NY, Zhang N, Hu GQ, Xie FY, Sun Y, Chen XZ, Li JG, Zhu XD et al: Induction chemotherapy plus concurrent chemoradiotherapy versus concurrent chemoradiotherapy alone in locoregionally advanced nasopharyngeal carcinoma: a phase 3, multicentre, randomised controlled trial. The Lancet Oncology 2016, 17(11):1509-1520.

7. Yang Q, Cao SM, Guo L, Hua YJ, Huang PY, Zhang XL, Lin M, You R, Zou X, Liu YP et al: Induction chemotherapy followed by concurrent chemoradiotherapy versus concurrent chemoradiotherapy alone in locoregionally advanced nasopharyngeal carcinoma: long-term results of a phase III multicentre randomised controlled trial. European journal of cancer (Oxford, England: 1990) 2019, 119:87-96.

8. Lee AW, Tung SY, Ngan RK, Chappell R, Chua DT, Lu TX, Siu L, Tan T, Chan LK, Ng WT et al: Factors contributing to the efficacy of concurrent-adjuvant chemotherapy for locoregionally advanced nasopharyngeal carcinoma: combined analyses of NPC-9901 and NPC-9902 Trials. European journal of cancer (Oxford, England: 1990) 2011, 47(5):656-666.

9. Loong HH, Ma BB, Leung SF, Mo F, Hui EP, Kam MK, Chan SL, Yu BK, Chan AT: Prognostic significance of the total dose of cisplatin administered during concurrent chemoradiotherapy in patients with locoregionally advanced nasopharyngeal carcinoma. Radiotherapy and oncology: journal of the European Society for Therapeutic Radiology and Oncology 2012, 104(3):300-304.

10. Ang KK: Concurrent radiation chemotherapy for locally advanced head and neck carcinoma: are we addressing burning subjects? Journal of clinical oncology: official journal of the American Society of Clinical Oncology 2004, 22(23):4657-4659.

11. Peng H, Chen L, Li WF, Guo R, Mao YP, Zhang Y, Guo Y, Sun Y, Ma J: Tumor response to neoadjuvant chemotherapy predicts long-term survival outcomes in patients with locoregionally advanced nasopharyngeal carcinoma: A secondary analysis of a randomized phase 3 clinical trial. Cancer 2017, 123(9):1643-1652.

12. Liu SL, Sun XS, Yan JJ, Chen QY, Lin HX, Wen YF, Guo SS, Liu LT, Xie HJ, Tang QN et al: Optimal cumulative cisplatin dose in nasopharyngeal carcinoma patients based on induction chemotherapy 
response. Radiotherapy and oncology: journal of the European Society for Therapeutic Radiology and Oncology 2019, 137:83-94.

13. Wei W, Huang Z, Li S, Chen H, Zhang G, Li S, Hu W, Xu T: Pretreatment Epstein-Barr virus DNA load and cumulative cisplatin dose intensity affect long-term outcome of nasopharyngeal carcinoma treated with concurrent chemotherapy: experience of an institute in an endemic area. Oncology research and treatment 2014, 37(3):88-95.

14. Matsumoto I, Murakami Y, Shinzeki M, Asari S, Goto T, Tani M, Motoi F, Uemura K, Sho M, Satoi S et al: Proposed preoperative risk factors for early recurrence in patients with resectable pancreatic ductal adenocarcinoma after surgical resection: A multi-center retrospective study. Pancreatology: official journal of the International Association of Pancreatology (IAP) [et al] 2015, 15(6):674-680.

15. Calderaro J, Petitprez F, Becht E, Laurent A, Hirsch TZ, Rousseau B, Luciani A, Amaddeo G, Derman J, Charpy $C$ et al: Intra-tumoral tertiary lymphoid structures are associated with a low risk of early recurrence of hepatocellular carcinoma. Journal of hepatology 2019, 70(1):58-65.

16. Li F, Chen FP, Chen YP, Chen Y, He XJ, Huang XD, Zheng ZQ, Zheng WH, Liu X, Sun Y et al: Clinical Characteristics and Prognostic Factors of Early and Late Recurrence After Definitive Radiotherapy for Nasopharyngeal Carcinoma. Frontiers in oncology 2020, 10:1469.

17. Llamas-Olier AE, Cuéllar DI, Buitrago G: Intermediate-Risk Papillary Thyroid Cancer: Risk Factors for Early Recurrence in Patients with Excellent Response to Initial Therapy. Thyroid: official journal of the American Thyroid Association 2018, 28(10):1311-1317.

18. Speers C, Chang SL, Pesch A, Ritter C, Olsen E, Chandler B, Moubadder L, Liu M, Cameron M, Michmerhuizen A et al: A Signature That May Be Predictive of Early Versus Late Recurrence After Radiation Treatment for Breast Cancer That May Inform the Biology of Early, Aggressive Recurrences. International journal of radiation oncology, biology, physics 2020, 108(3):686-696.

19. Groot VP, Gemenetzis G, Blair AB, Rivero-Soto RJ, Yu J, Javed AA, Burkhart RA, Rinkes I, Molenaar IQ, Cameron JL et al: Defining and Predicting Early Recurrence in 957 Patients With Resected Pancreatic Ductal Adenocarcinoma. Annals of surgery 2019, 269(6):1154-1162.

20. Xu BB, Lu J, Zheng ZF, Xie JW, Wang JB, Lin JX, Chen QY, Cao LL, Lin M, Tu RH et al: The predictive value of the preoperative $\mathrm{C}$-reactive protein-albumin ratio for early recurrence and chemotherapy benefit in patients with gastric cancer after radical gastrectomy: using randomized phase III trial data. Gastric cancer: official journal of the International Gastric Cancer Association and the Japanese Gastric Cancer Association 2019, 22(5):1016-1028.

21. Kim HG, Kim HS, Yang SY, Han YD, Cho MS, Hur H, Min BS, Lee KY, Kim NK: Early recurrence after neoadjuvant chemoradiation therapy for locally advanced rectal cancer: Characteristics and risk factors. Asian journal of surgery 2021, 44(1):298-302.

22. Zhou GQ, Wu CF, Deng B, Gao TS, Lv JW, Lin L, Chen FP, Kou J, Zhang ZX, Huang XD et al: An optimal posttreatment surveillance strategy for cancer survivors based on an individualized risk-based approach. Nature communications 2020, 11(1):3872. 
23. Rice TW, Rusch VW, Ishwaran H, Blackstone EH: Cancer of the esophagus and esophagogastric junction: data-driven staging for the seventh edition of the American Joint Committee on Cancer/International Union Against Cancer Cancer Staging Manuals. Cancer 2010, 116(16):37633773.

24. Taylor JM: Random Survival Forests. Journal of thoracic oncology: official publication of the International Association for the Study of Lung Cancer 2011, 6(12):1974-1975.

25. Random Forest SRC: random forests for survival, regression and classification. [ https://CRAN.Rproject.org/package=randomForestSRC.]

26. Kang WM, Meng QB, Yu JC, Ma ZQ, Li ZT: Factors associated with early recurrence after curative surgery for gastric cancer. World journal of gastroenterology 2015, 21(19):5934-5940.

27. Nishio K, Kimura K, Amano R, Yamazoe S, Ohrira G, Nakata B, Hirakawa K, Ohira M: Preoperative predictors for early recurrence of resectable pancreatic cancer. World journal of surgical oncology 2017, 15(1):16.

28. Giacona MB, Ruben GC, Iczkowski KA, Roos TB, Porter DM, Sorenson GD: Cell-free DNA in human blood plasma: length measurements in patients with pancreatic cancer and healthy controls. Pancreas 1998, 17(1):89-97.

29. Stroun M, Lyautey J, Lederrey C, Olson-Sand A, Anker P: About the possible origin and mechanism of circulating DNA apoptosis and active DNA release. Clinica chimica acta; international journal of clinical chemistry 2001, 313(1-2):139-142.

30. Jiang N, Reich CF, 3rd, Pisetsky DS: Role of macrophages in the generation of circulating blood nucleosomes from dead and dying cells. Blood 2003, 102(6):2243-2250.

31. Tang LQ, Li CF, Li J, Chen WH, Chen QY, Yuan LX, Lai XP, He Y, Xu YX, Hu DP et al: Establishment and Validation of Prognostic Nomograms for Endemic Nasopharyngeal Carcinoma. Journal of the National Cancer Institute 2016, 108(1).

32. Zhang LL, Huang MY, Fei X, Wang KX, Song D, Wang T, Sun LY, Shao JY: Risk stratification for nasopharyngeal carcinoma: a real-world study based on locoregional extension patterns and Epstein-Barr virus DNA load. Therapeutic advances in medical oncology 2020,

12:1758835920932052.

33. Lu ZX, Ma XQ, Yang LF, Wang ZL, Zeng L, Li ZJ, Li XN, Tang M, Yi W, Gong JP et al: DNAzymes targeted to EBV-encoded latent membrane protein-1 induce apoptosis and enhance radiosensitivity in nasopharyngeal carcinoma. Cancer letters 2008, 265(2):226-238.

34. Zhai X, Yang Y, Wan J, Zhu R, Wu Y: Inhibition of LDH-A by oxamate induces G2/M arrest, apoptosis and increases radiosensitivity in nasopharyngeal carcinoma cells. Oncology reports 2013, 30(6):2983-2991.

35. Yang S, Chen J, Guo Y, Lin H, Zhang Z, Feng G, Hao Y, Cheng J, Liang P, Chen K et al: Identification of prognostic biomarkers for response to radiotherapy by DNA microarray in nasopharyngeal carcinoma patients. International journal of oncology 2012, 40(5):1590-1600. 
36. Sargent D, Sobrero A, Grothey A, O'Connell MJ, Buyse M, Andre T, Zheng Y, Green E, Labianca R, $O$ 'Callaghan $C$ et al: Evidence for cure by adjuvant therapy in colon cancer. observations based on individual patient data from 20,898 patients on 18 randomized trials. Journal of clinical oncology: official journal of the American Society of Clinical Oncology 2009, 27(6):872-877.

37. Bentzen SM, Harari PM, Bernier J: Exploitable mechanisms for combining drugs with radiation: concepts, achievements and future directions. Nature clinical practice Oncology 2007, 4(3):172-180.

38. Peng L, Xu C, Chen YP, Guo R, Mao YP, Sun Y, Ma J, Tang LL: Optimizing the cumulative cisplatin dose during radiotherapy in nasopharyngeal carcinoma: Doseeffect analysis for a large cohort. Oral oncology 2019, 89:102-106.

39. Lv JW, Qi ZY, Zhou GQ, He XJ, Chen YP, Mao YP, Chen L, Tang LL, Li WF, Lin AH et al: Optimal cumulative cisplatin dose in nasopharyngeal carcinoma patients receiving additional induction chemotherapy. Cancer science 2018, 109(3):751-763.

\section{Tables}

Table 1. Patient demographics and clinical characteristics. 


\begin{tabular}{|c|c|c|c|c|c|}
\hline \multirow[t]{2}{*}{ Characteristic } & \multicolumn{3}{|c|}{ No. of patients } & \multirow[t]{2}{*}{ Total } & \multirow[t]{2}{*}{$P$ value } \\
\hline & $C C D=0$ & CCDD1-200] & $C C D>200$ & & \\
\hline & $708(22.7 \%)$ & $2230(77.3 \%)$ & $185(5.9 \%)$ & $3123(100 \%)$ & \\
\hline Sex & & & & & 0.417 \\
\hline Male & $518(73.2 \%)$ & 1663(74.6\%) & $144(77.8 \%)$ & $2325(74.4 \%)$ & \\
\hline Female & $190(26.8 \%)$ & $567(25.4 \%)$ & $41(22.2)$ & $798(25.6 \%)$ & \\
\hline Histology & & & & & 0.550 \\
\hline WHO Type I-II & $22(3.1 \%)$ & $63(2.8 \%)$ & $3(1.6 \%)$ & $87(2.8 \%)$ & \\
\hline WHO Type III & $687(96.9 \%)$ & 2168(97.2\%) & 182(98.4\%) & $3036(97.2 \%)$ & \\
\hline Age, year & & & & & $<0.001$ \\
\hline$\leq 45$ & $319(45.1 \%)$ & 1246 (55.9\%) & $129(69.7 \%)$ & $1694(54.2 \%)$ & \\
\hline$\varangle 45$ & $389(54.9 \%)$ & $1040(44.1 \%)$ & $56(30.3 \%)$ & $1429(45.7 \%)$ & \\
\hline Smoking history & & & & & 0.001 \\
\hline No & $463(65.4 \%)$ & $1352(60.6 \%)$ & $135(73.0 \%)$ & $1950(62.4 \%)$ & \\
\hline Yes & $245(34.6 \%)$ & $878(39.4 \%)$ & $50(27.1 \%)$ & $1173(37.6 \%)$ & \\
\hline Drinking history & & & & & 0.025 \\
\hline No & $628(88.7 \%)$ & 1887(84.6\%) & $160(86.5 \%)$ & $2675(85.6 \%)$ & \\
\hline Yes & $80(11.3 \%)$ & $343(15.4 \%)$ & $25(13.5 \%)$ & $448(14.4 \%)$ & \\
\hline Family history of & ancer & & & & 0.158 \\
\hline No & $535(75.6 \%)$ & $1644(73.7 \%)$ & $127(68.6 \%)$ & $2306(73.8 \%)$ & \\
\hline Yes & $173(24.4 \%)$ & $586(26.3 \%)$ & $58(31.4 \%)$ & $817(26.2 \%)$ & \\
\hline T stage ${ }^{\star *}$ & & & & & 0.461 \\
\hline T1-2 & $99(14.0 \%)$ & $287(12.9 \%)$ & $29(15.7 \%)$ & $415(13.3 \%)$ & \\
\hline T3-4 & $609(86.0 \%)$ & 1943(87.1\%) & $156(84.3 \%)$ & 2708(86.7\%) & \\
\hline N stage** & & & & & 0.007 \\
\hline N0-1 & $369(52.1 \%)$ & $1028(46.1 \%)$ & $98(53.0 \%)$ & $1495(47.9 \%)$ & \\
\hline N2-3 & $339(47.9 \%)$ & 1202(53.9\%) & $87(47.0 \%)$ & $1628(52.1 \%)$ & \\
\hline Overall stage & & & & & $<0.001$ \\
\hline III & $423(59.7 \%)$ & 1035 (46.4\%) & $78(42.2 \%)$ & $1536(49.1 \%)$ & \\
\hline
\end{tabular}




\begin{tabular}{|c|c|c|c|c|c|}
\hline IVa & $285(40.3 \%)$ & $1195(53.6 \%)$ & $107(57.8 \%)$ & $1587(50.8 \%)$ & \\
\hline \multicolumn{5}{|c|}{ EBV DNA load, copy/ml } & 0.151 \\
\hline$<4000$ & $325(45.9 \%)$ & $932(41.8 \%)$ & $81(43.8 \%)$ & $1338(42.8 \%)$ & \\
\hline$\geq 4000$ & $383(54.1 \%)$ & $1298(58.2 \%)$ & $104(56.2 \%)$ & 1785(57.2\%) & \\
\hline IC cycles & & & & & $<0.001$ \\
\hline$\leq 2$ cycles & $465(65.7 \%)$ & $1226(55.0 \%)$ & $67(36.2 \%)$ & $1758(56.3 \%)$ & \\
\hline$>2$ cycles & $243(34.3 \%)$ & $1004(45.0 \%)$ & $118(63.8 \%)$ & $1365(43.7 \%)$ & \\
\hline ELRF & & & & & 0.950 \\
\hline No & $694(98.0 \%$ & 2188(98.1\%) & 182(98.4\%) & $3064(98.1 \%)$ & \\
\hline Yes & $14(2.0 \%)$ & $42(1.9 \%)$ & $3(1.6 \%)$ & $59(1.9 \%)$ & \\
\hline LLRF & & & & & 0.485 \\
\hline No & $621(87.7 \%)$ & 1987(89.1\%) & $167(90.3 \%)$ & $2775(88.9 \%)$ & \\
\hline Yes & $87(12.3 \%)$ & $243(10.9 \%)$ & $18(9.7 \%)$ & $348(11.1 \%)$ & \\
\hline EDF & & & & & 0.045 \\
\hline No & $636(89.8 \%)$ & 2032(91.1\%) & $177(95.7 \%)$ & 2845(91.1\%) & \\
\hline Yes & $72(10.2 \%)$ & 198(8.9\%) & $8(4.3 \%)$ & $278(8.9 \%)$ & \\
\hline LDF & & & & & 0.700 \\
\hline No & $653(92.2 \%)$ & $2063(92.5 \%)$ & $174(94.1 \%)$ & $2890(92.5 \%)$ & \\
\hline Yes & $55(7.8 \%)$ & $167(7.5 \%)$ & $11(5.9 \%)$ & $233(7.5 \%)$ & \\
\hline
\end{tabular}

Abbreviations: ELRF = early locoregional failure; LLRF = late locoregional failure; $E D F=$ early distant failure; $\mathrm{LDF}=$ late distant failure; $\mathrm{WHO}=$ World Health Organization; $\mathrm{EBV}=$ Epstein - Barr virus; $\mathrm{CCD}=$ cumulative cisplatin dose.

* Percentages may not add up to 100 due to rounding.

${ }^{\star \star}$ According to the 8th edition of the American Joint Commission on Cancer staging system.

Table 2. Univariate and multivariate analysis of post-failure prognostic factors in the distant failure group. 


\begin{tabular}{|c|c|c|c|c|}
\hline & Ultivariable analysis & & Multivariable analys & \\
\hline Variable & $\mathrm{HR} 95 \% \mathrm{Cl}$ & $P$ value & $\mathrm{HR} 95 \% \mathrm{Cl}$ & $P$ value \\
\hline SexDFemale vs. Male) & $1.170(0.910-1.503)$ & 0.220 & NA & \\
\hline WHO Histology (I II vs. III) & $1.027(0.648-1.629)$ & 0.908 & NA & \\
\hline Age, year ( $\leq 45 v s .045)$ & $0.728(0.597-0.888)$ & 0.002 & NA & \\
\hline T stage*( T3-4 vs. T1-2) & $1.029(0.782-1.355)$ & 0.837 & NA & \\
\hline N stage*( N2-3 vs. N0-1) & $1.178(0.947-1.466)$ & 0.141 & NA & \\
\hline Overall stage*( IVa vs. III) & $1.089(0.886-1.338)$ & 0.418 & NA & \\
\hline $\begin{array}{l}\text { EBV DNA load, copy/ml } \\
(\geq 4000 \text { vs. }<4000)\end{array}$ & $1.209(0.965-1.514)$ & 0.098 & NA & \\
\hline IC cycle(2cycle vs. $>2$ cycle) & $0.925(0.759-1.128)$ & 0.440 & NA & \\
\hline $\mathrm{CCD}, \mathrm{mg} / \mathrm{m}^{2}$ & & 0.505 & NA & \\
\hline 0 & Reference & & & \\
\hline $1-200$ & $0.899(0.717-1.128)$ & 0.359 & & \\
\hline$>200$ & $0.748(0.411-1.361)$ & 0.341 & & \\
\hline EDFFS & $1.472(1.199-1.907)$ & $<0.001$ & $1.375(1.118-1.691)$ & 0.003 \\
\hline Post treatment & & $<0.001$ & & $<0.001$ \\
\hline Supportive treatment & Reference & & & \\
\hline Surgery & $0.128(0.084-0.197)$ & $<0.001$ & $0.134(0.087-0.205)$ & $<0.001$ \\
\hline Radiotherapy & $0.291(0.191-0.444)$ & $<0.001$ & $0.198(0.198-0.459)$ & $<0.001$ \\
\hline Chemotherapy & $0.255(0.201-0.325)$ & $<0.001$ & $0.259(0.203-0.329)$ & $<0.001$ \\
\hline Comprehensive therapy & $0.090(0.049-0.165)$ & $<0.001$ & $0.093(0.051-0.169)$ & $<0.001$ \\
\hline unknown & $0.176(0.072-0.433)$ & $<0.001$ & $0.205(0.083-0.507)$ & 0.001 \\
\hline
\end{tabular}

Abbreviations: $\mathrm{HR}$ = hazard ratio; $\mathrm{Cl}=$ confidence interval; $\mathrm{WHO}=$ World Health Organization; $\mathrm{EBV}=$ Epstein-Barr virus; $C C D$ = cumulative cisplatin dose; EDFFS = early distant failure-free survival.

*According to the 8th edition of the American Joint Commission on Cancer staging system.

Table 3. Univariate and multivariate analysis of post-failure prognostic factors in the locoregional recurrence group. 


\begin{tabular}{|c|c|c|c|c|}
\hline & ultivariable analysis & & Multivariable analys & \\
\hline Variable & $\mathrm{HR} 95 \% \mathrm{Cl}$ & $P$ value & $\mathrm{HR} 95 \% \mathrm{Cl}$ & $P$ value \\
\hline Sex[Female vs. Male) & $0.888(0.642-1.229)$ & 0.474 & & \\
\hline WHO Histology (I II vs. III) & $0.729(0.902-1.614)$ & 0.729 & & \\
\hline Age, year ( $\square 45$ vs. $\leq 45)$ & $1.092(0.841-1.419)$ & 0.508 & & \\
\hline T stage*( T3-4 vs. T1-2) & $1.112(0.722-1.712)$ & 0.629 & & \\
\hline N stage*( N2-3 vs. N0-1) & $0.861(0.662-1.118)$ & 0.262 & & \\
\hline Overall stage*( IVa vs. III) & $1.611(1.223-2.121)$ & $<0.001$ & $1.544(1.166-2.044 \rrbracket$ & 0.002 \\
\hline $\begin{array}{l}\text { EBV DNA load, copy/ml } \\
(\geq 4000 \text { vs. }<4000)\end{array}$ & $1.085(0.825-1.427)$ & 0.559 & & \\
\hline IC cycle(>2 cycle vs. 2 cycle) & $0.983(0.757-1.277)$ & 0.898 & & \\
\hline $\mathrm{CCD}, \mathrm{mg} / \mathrm{m}^{2}$ & & 0.746 & & \\
\hline 0 & Reference & & & \\
\hline $1-200$ & $0.954(0.703-1.293)$ & 0.761 & & \\
\hline$>200$ & $0.760(0.376-1.537)$ & 0.446 & & \\
\hline ELRFFS & $1.640(1.230-2.185)$ & 0.001 & $1.833(1.367-2.458 \otimes$ & $<0.001$ \\
\hline Post treatment & & $<0.001$ & & $<0.001$ \\
\hline Supportive treatment & Reference & & & \\
\hline surgery & $0.165(0.095-0.284)$ & $<0.001$ & $0.144(0.083-0.251)$ & $<0.001$ \\
\hline radiotherapy & $0.358(0.223-0.575)$ & $<0.001$ & $0.360(0.224-0.578)$ & $<0.001$ \\
\hline Chemotherapy & $0.555(0.354-0.869)$ & 0.010 & $0.483(0.306-0.761)$ & 0.002 \\
\hline Comprehensive treatment & $0.486(0.115-2.057)$ & 0.327 & $0.554(0.131-2.348)$ & 0.422 \\
\hline Unknown & $0.391(0.053-2.896)$ & 0.358 & $0.359(0.048-2.668)$ & 0.317 \\
\hline
\end{tabular}

Abbreviations: $\mathrm{HR}$ = hazard ratio; $\mathrm{Cl}=$ confidence interval; $\mathrm{WHO}=$ World Health Organization; $\mathrm{EBV}=$ Epstein-Barr virus; $C C D$ = cumulative cisplatin dose; ELRFFS = early locoregional failure- free survival.

*According to the 8th edition of the American Joint Commission on Cancer staging system.

Table 4. Multivariable analysis of prognostic factors for the entire cohort. 


\begin{tabular}{|c|c|c|c|c|}
\hline End point & Variable & HR & $95 \% \mathrm{Cl}$ & P-value \\
\hline \multirow[t]{10}{*}{ OS } & Sex[Male vs. Female) & 0.722 & $0.592-0.882$ & 0.001 \\
\hline & WHO Histology (I I| vs. III) & 0.643 & $0.443-0.935$ & 0.021 \\
\hline & Age, year ( $(445$ vs. $\leq 45)$ & 1.400 & 1.193-1.642 & $<0.001$ \\
\hline & N stage*( N2-3 vs. N0-1) & 1.417 & 1.199-1.674 & $<0.001$ \\
\hline & Overall stage*( IVa vs. III) & 1.694 & $1.430-2.007$ & $<0.001$ \\
\hline & EBV DNA load, copy/ml ( $\geq 4000$ vs. $<4000)$ & 1.462 & $1.228-1.741$ & $<0.001$ \\
\hline & $\mathrm{CCD}, \mathrm{mg} / \mathrm{m}^{2}$ & & & \\
\hline & 0 & Reference & & \\
\hline & $1-200$ & 0.728 & $0.609-0.872$ & 0.001 \\
\hline & $>200$ & 0.415 & $0.263-0.6550$ & $<0.001$ \\
\hline \multirow[t]{10}{*}{ DFS } & SexロMale vs. Female) & 0.713 & $0.605-0.840$ & $<0.001$ \\
\hline & WHO Histology (I I| vs. III) & 0.627 & $0.454-0.865$ & 0.004 \\
\hline & Age, year ( $145 v s . \leq 45)$ & 1.195 & $1.046-1.363$ & 0.008 \\
\hline & N stage*( N2-3 vs. N0-1) & 1.297 & $1.131-1.488$ & $<0.001$ \\
\hline & Overall stage*( IVa vs. III) & 1.535 & $1.336-1.765$ & $<0.001$ \\
\hline & EBV DNA, copy/ml ( $\geq 4000$ vs. $<4000)$ & 1.387 & $1.203-1.599$ & $<0.001$ \\
\hline & $\mathrm{CCD}, \mathrm{mg} / \mathrm{m}^{2}$ & & & \\
\hline & 0 & Reference & & \\
\hline & $1-200$ & 0.778 & $0.668-0.906$ & 0.001 \\
\hline & $>200$ & 0.531 & $0.376-0.750$ & $<0.001$ \\
\hline \multirow[t]{2}{*}{ LRFFS } & WHO Histology (I I| vs. III) & 0.610 & $0.380-0.979$ & 0.040 \\
\hline & Overall stage*( IVa vs. III) & 1.449 & $1.185-1.773$ & $<0.001$ \\
\hline ELRRFS & WHO Histology (I I| vs. III) & 0.354 & $0.144-0.874$ & 0.024 \\
\hline \multirow[t]{2}{*}{ LLRRFS } & Age, year ( $(445$ vs. $\leq 45)$ & 1.324 & $1.063-1.649$ & 0.012 \\
\hline & Overall stage*( IVa vs. III) & 1.427 & $1.138-1.790$ & 0.002 \\
\hline DMFS & N stage*(N0-1 vs.N2-3) & 4.037 & $2.207-7.383$ & $<0.001$ \\
\hline \multirow[t]{2}{*}{ EDMFS } & Sex[Male vs. Female) & 0.674 & 0.497-0.913 & 0.011 \\
\hline & N stage*( N2-3 vs. N0-1) & 2.160 & $1.646-2.833$ & $<0.001$ \\
\hline
\end{tabular}




\begin{tabular}{|c|c|c|c|c|}
\hline & Overall stage*( IVa vs. III) & 1.376 & $1.070-1.770$ & 0.013 \\
\hline & EBV DNA, copy/ml $(\geq 4000$ vs. $<4000)$ & 2.152 & $1.615-2.867$ & $<0.001$ \\
\hline & $\mathrm{CCD}, \mathrm{mg} / \mathrm{m}^{2}$ & & & \\
\hline & 0 & Reference & & \\
\hline & $1-200$ & 0.763 & $0.581-1.002$ & 0.052 \\
\hline & $>200$ & 0.351 & $0.169-0.732$ & 0.005 \\
\hline \multirow[t]{4}{*}{ LDMFS } & Sex凸Male vs. Female) & 0.667 & $0.480-0.926$ & 0.016 \\
\hline & WHO Histology (| I| vs. III) & 0.481 & $0.275-0.843$ & 0.011 \\
\hline & N stage*( N2-3 vs. N0-1) & 1.549 & $1.184-2.025$ & 0.001 \\
\hline & Overall stage*( IVa vs. III) & 1.608 & $1.230-2.102$ & 0.001 \\
\hline
\end{tabular}

Abbreviations: $\mathrm{HR}$ = hazard ratio; $\mathrm{Cl}=$ confidence interval; $\mathrm{OS}$ = overall survival; $\mathrm{DFS}$ = disease- free survival; ELRFFS = early locoregional failure- free survival; LLRFFS = late locoregional failure- free survival; EDFFS = early distant failure-free survival; LDFFS= late distant failure-free survival; WHO = World Health Organization; EBV = Epstein-Barr virus; $\mathrm{CCD}=$ cumulative cisplatin dose.

A Cox proportional hazards regression model was used to detect variables individually without adjustment. All variables were transformed into categorical variables. HRs were calculated for sex, WHO Histology, age, Family history, T stage, $\mathrm{N}$ stage, clinical stage, EBV-DNA before treatment, IC cycle, CCD.

*According to the 8th edition of the American Joint Commission on Cancer staging system.

\section{Figures}


A

Cut-off value in month of locoregional failure -free survival

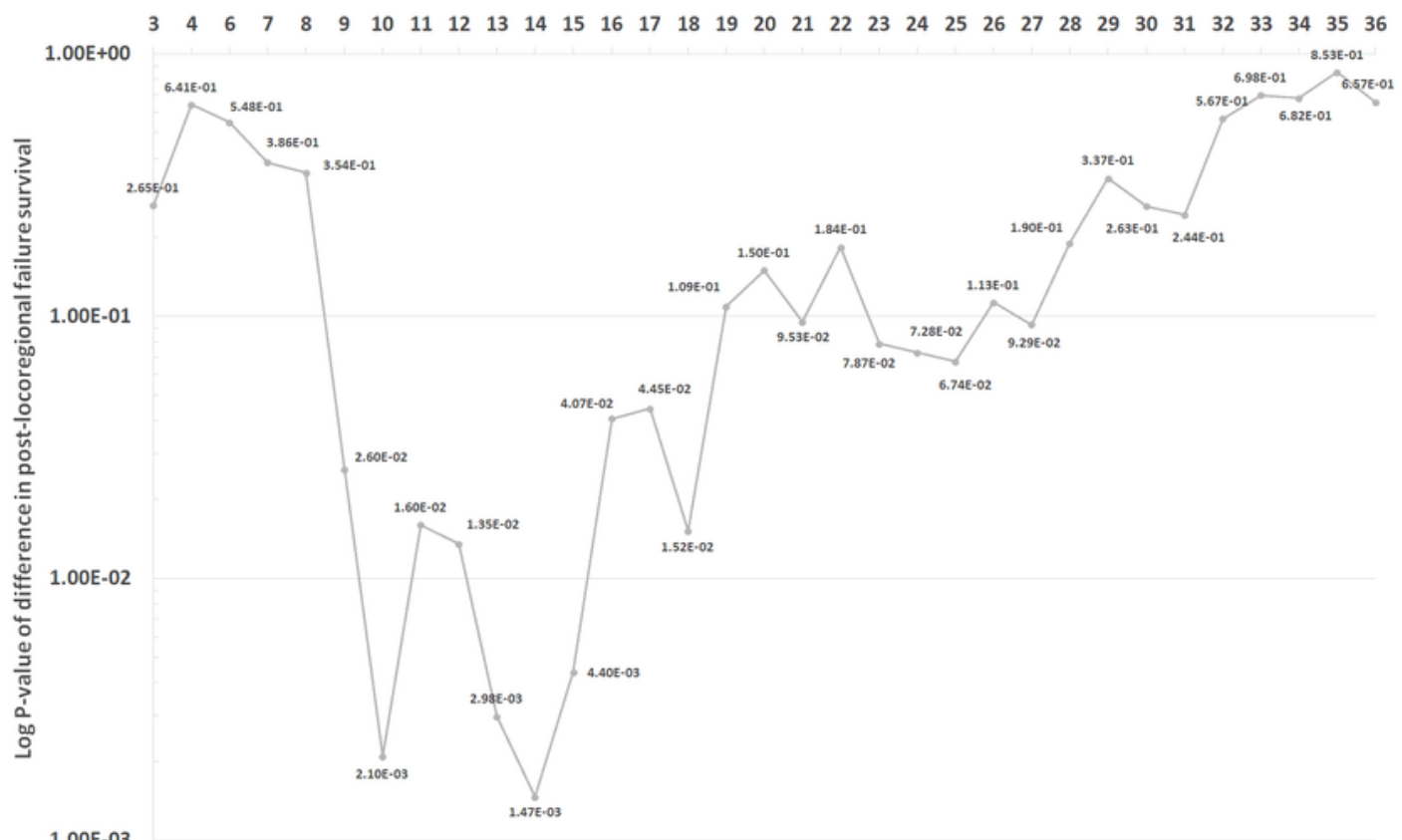

B

Cut-off value in months of distant failure-free survival

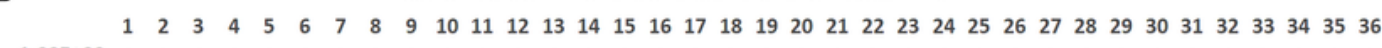
$1.00 E+00$

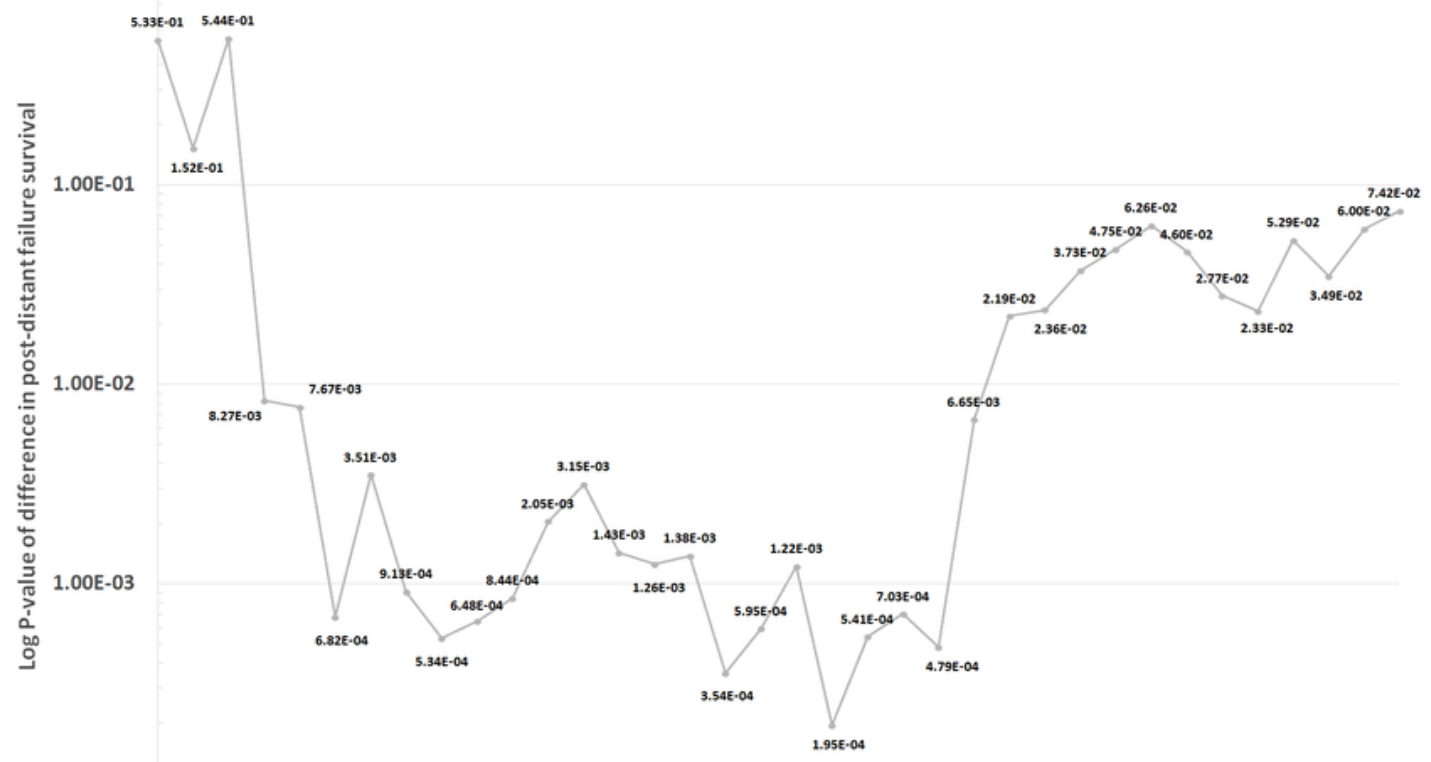

$1.00 E-04$

\section{Figure 1}

Different cut-off thresholds with corresponding $P$ values for locoregional failure $(A)$ and distant failure (B). 
A

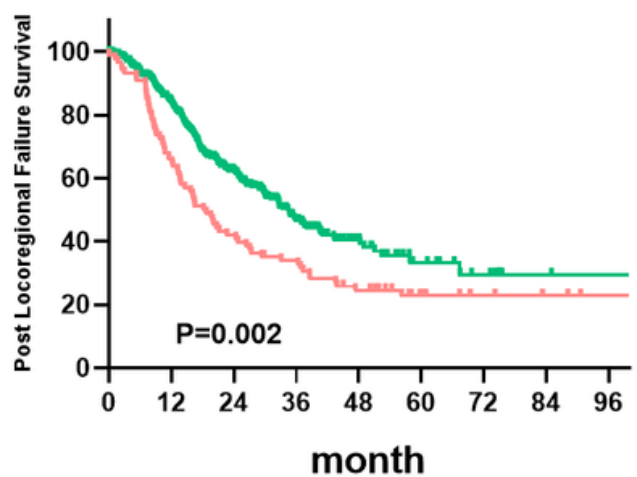

$\begin{array}{lccccccccc}\text { ELRF } & 88 & 60 & 38 & 30 & 21 & 10 & 6 & 4 & 1 \\ \text { LLRF } & 319 & 253 & 151 & 87 & 37 & 14 & 8 & 3 & 1\end{array}$
B

- ELRF

- LLRF

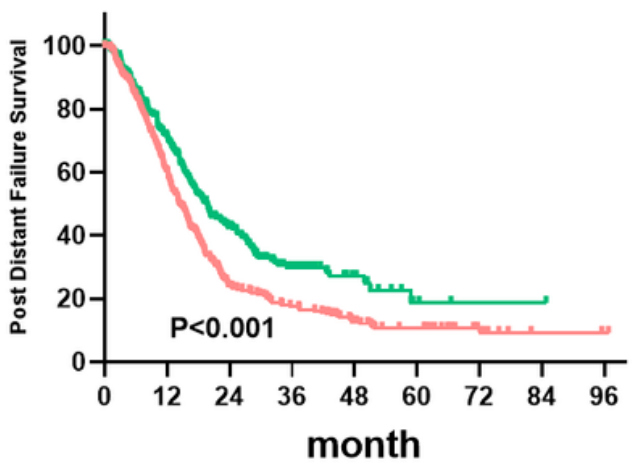

$\begin{array}{lrrrrrrrrr}\text { EDF } & 278 & 168 & 68 & 49 & 30 & 20 & 8 & 2 & 1 \\ \text { LDF } & 233 & 152 & 79 & 36 & 14 & 3 & 2 & 1 & 0\end{array}$

\section{Figure 2}

Kaplan-Meier analysis of post-failure survival in 407 patients with locoregional failure stratified by early (ELRF) and late locoregional failure(ELRF) (A); 511 patients with distant failure stratified by early (EDF) and late distant failure(LDF) (B).

A

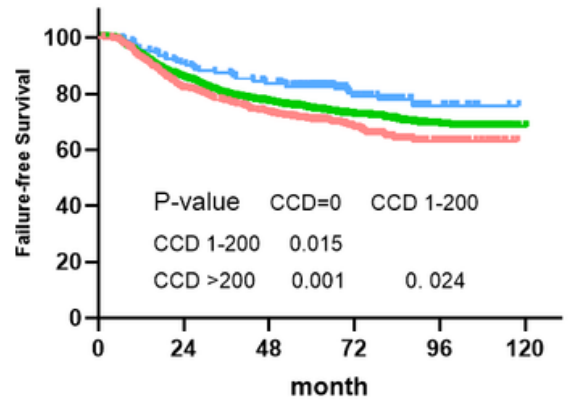

$\begin{array}{lrcrrll}\text { CCD }=0 & 708 & 582 & 516 & 234 & 50 & 0 \\ \text { CCD 1-200 } & 2230 & 1907 & 1680 & 754 & 215 & 2 \\ \text { CCD }>200 & 185 & 168 & 152 & 88 & 21 & 0\end{array}$

C

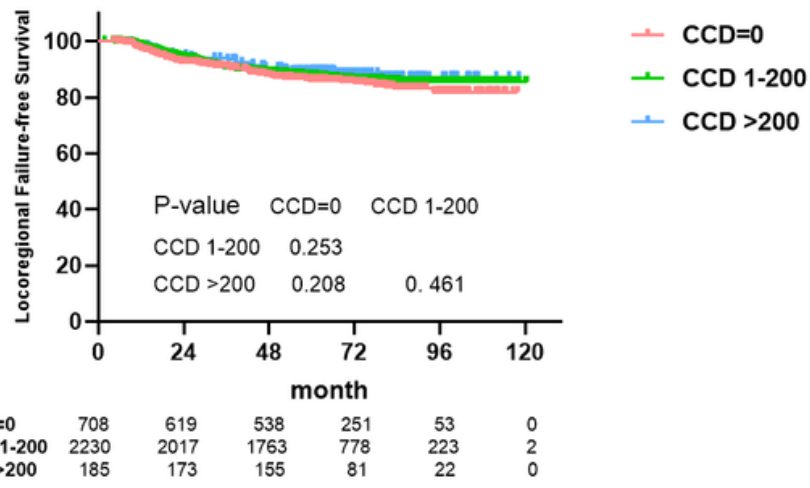

B

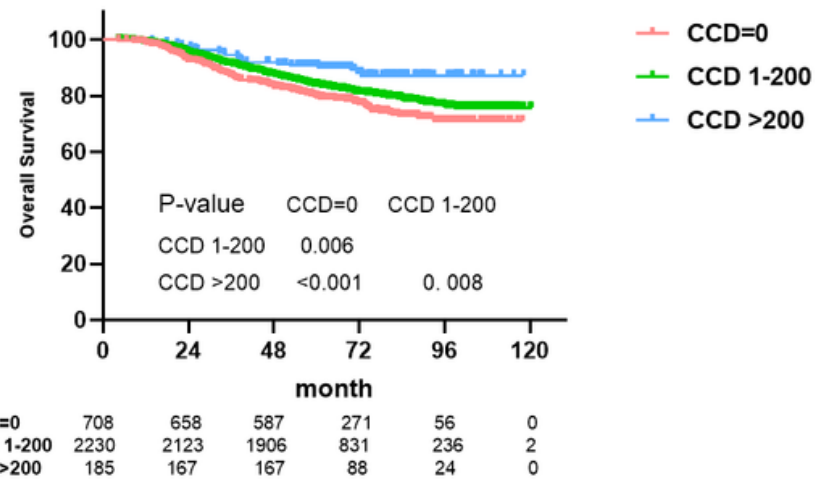

D

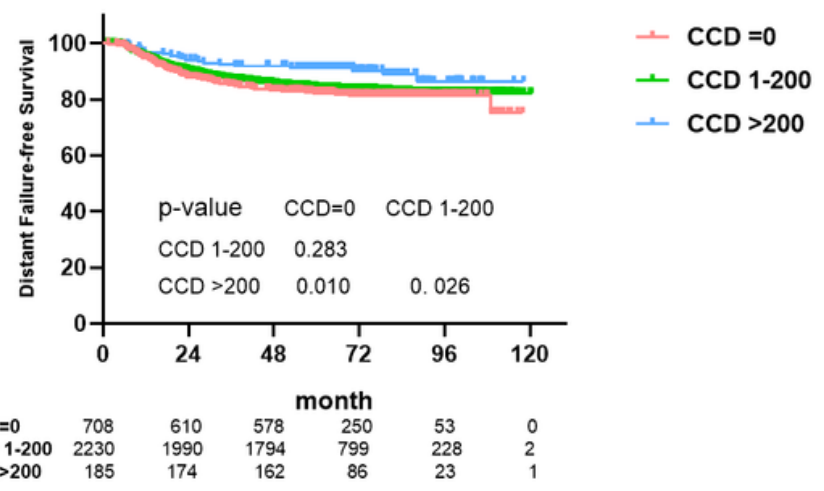

Figure 3 
Kaplan-Meier FFS (A), OS (B), LRFS (C) and DMFS (D) curves in 3123 LANPC patients stratified by CCD = $0 \mathrm{mg} / \mathrm{m} 2$, CCD 1-200 mg/m2, and CCD >200 mg/m2.
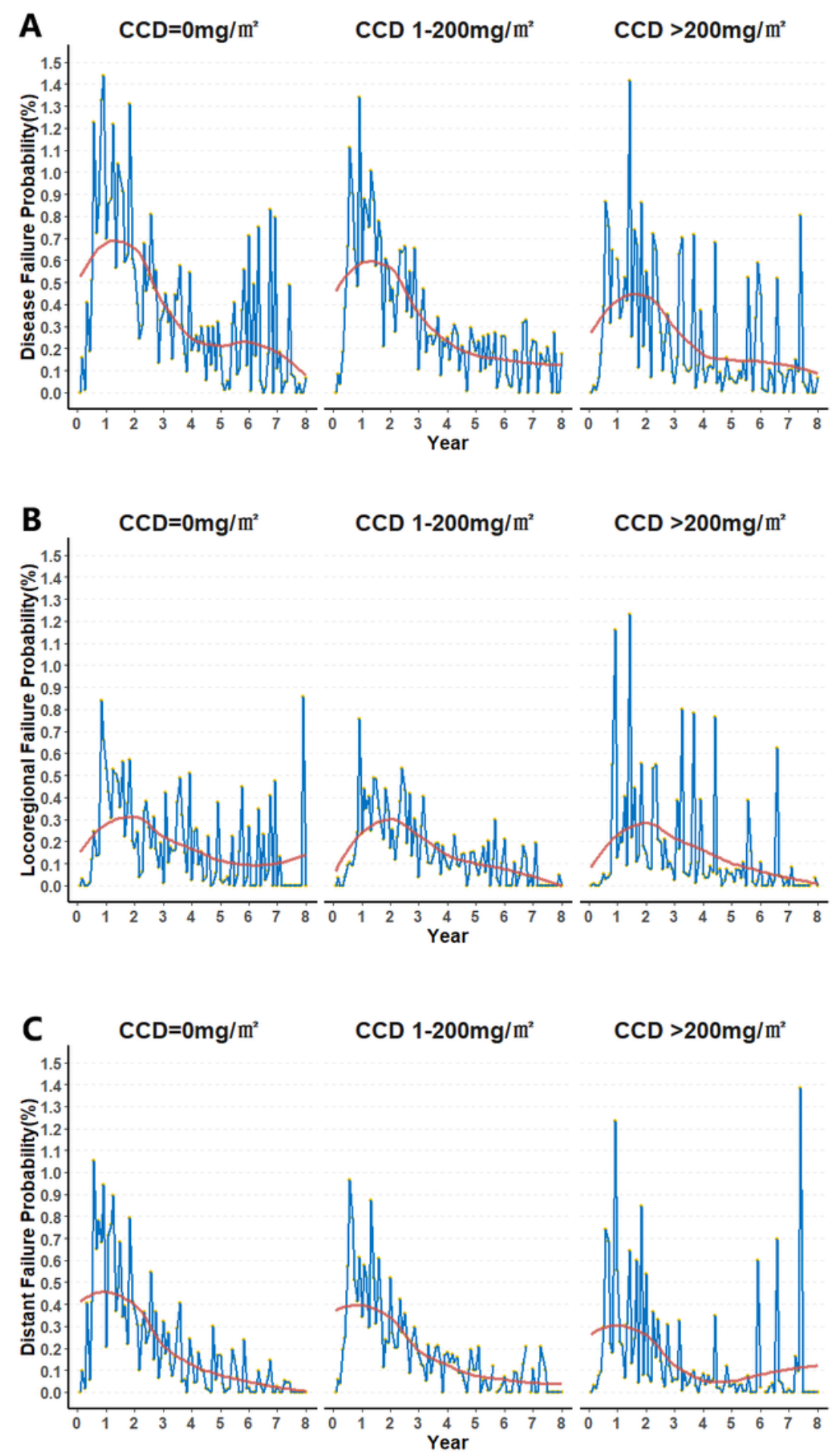

Figure 4

Time-specific treatment failure probabilities (A), locoregional failure (B), and distant failure probabilities (C) in 3123 nasopharyngeal carcinoma patients stratified by CCD $=0 \mathrm{mg} / \mathrm{m} 2$, CCD 1-200 mg/m2, and CCD $>200 \mathrm{mg} / \mathrm{m} 2$. 


\section{Supplementary Files}

This is a list of supplementary files associated with this preprint. Click to download.

- Supplementaryfiles1RcodeforminimumPvalueapproach.docx

- Supplementaryfiles2.tif 